OPEN ACCESS

Edited by:

Michel Audette,

Old Dominion University,

United States

Reviewed by:

Clement Hamani,

University of Toronto, Canada

Kareem Zaghloul,

National Institute of Neurological

Disorders and Stroke $(\mathrm{N} / \mathrm{H})$,

United States

*Correspondence:

Nicolas Kon Kam King nicolas.kon.k.k@singhealth.com.sg

Specialty section:

This article was submitted to Neurosurgery,

a section of the journal

Frontiers in Surgery

Received: 25 March 2017 Accepted: 06 September 2017 Published: 28 September 2017

Citation:

See AAQ and King NKK (2017) Improving Surgical Outcome Using Diffusion Tensor Imaging Techniques in Deep Brain Stimulation.

Front. Surg. 4:54.

doi: 10.3389/fsurg.2017.00054

\section{Improving Surgical Outcome Using Diffusion Tensor Imaging Techniques in Deep Brain Stimulation}

\author{
Angela An Qi See ${ }^{1}$ and Nicolas Kon Kam King ${ }^{1,2 *}$ \\ 'Department of Neurosurgery, National Neuroscience Institute, Singapore, Singapore, '2 Duke-NUS Medical School, \\ Singapore, Singapore
}

Introduction: Recent advances in surgical imaging include the use of diffusion tensor imaging (DTI) in deep brain stimulation (DBS) and provide a detailed view of the white matter tracts and their connections which are not seen with conventional magnetic resonance imaging. Given that the efficacy of DBS depends on the precise and accurate targeting of these circuits, better surgical planning using information obtained from DTI may lead to improved surgical outcome. We aim to review the available literature to evaluate the efficacy of such a strategy.

Methods: A search of PubMed was performed to identify all articles using the search terms "(diffusion tractography OR diffusion tensor imaging OR DTI) AND (deep brain stimulation OR DBS)." Studies were included if DTI was used and clinical outcomes were reported.

Results: We identified 35 studies where the use of DTI in DBS was evaluated. The most studied pathology was movement disorders (17 studies), psychiatric disorders (11 studies), and pain (7 studies). The overall responder rates for tremor reduction was $70.0 \%$ $(\mathrm{SD}=26.1 \%)$ in 69 patients, 36.5\% (SD = 19.1\%) for obsessive-compulsive disorder in 9 patients, $48.3 \%(S D=40.0 \%)$ for depression in 40 patients, and $49.7 \%(S D=35.1 \%)$ for chronic pain in 23 patients.

Discussion: The studies reviewed show that the use of DTI for surgical planning is feasible, provide additional information over conventional targeting methods, and can improve surgical outcome. Patients in whom the DBS electrodes were within the DTI targets experienced better outcomes than those in whom the electrodes were not. Many current studies are limited by their small sample size or retrospective nature. The use of DTI in DBS planning appears underutilized and further studies are warranted given that surgical outcome can be optimized using this non-invasive technique.

Keywords: deep brain stimulation, diffusion tensor imaging, diffusion tractography, magnetic resonance imaging, surgical outcomes

\section{INTRODUCTION}

Deep brain stimulation (DBS) is an established therapy for the treatment of medically refractory movement disorders including Parkinson's disease (1-3), essential tremor (4), and dystonia $(5,6)$. In recent years, it has gained increasing use as a treatment modality for psychiatric disorders such 
as depression and obsessive-compulsive disorder (OCD) (7-9), obesity (10), and memory disorders (11), as well as pain (12).

Conventional DBS surgical planning has been based on direct or indirect targeting combined with intraoperative electrophysiological recordings in order to locate targets in the deep brain structures. However, in indirect targeting, stereotactic coordinates derived from 2D histology-based human brain atlases are prone to spatial distortions. Further, in direct targeting, many DBS targets are in the internal subdivisions of thalamus and direct targeting or visualization using MRI is not feasible. Standard MRI also does not visualize white matter tracts.

Recent advances in surgical imaging include the use of diffusion tensor imaging (DTI) for surgical planning providing the surgeon with a detailed view of the white matter tracts and their connections. Diffusion tractography refers to 3D models of white matter pathways generated from diffusion weighted data, most commonly diffusion tensor imaging (DTI). Although diffusion tractography potentially suffers from a number of limitations including poor resolution, inaccuracies introduced by poor signal-to-noise ratio, possible misregistration with anatomic images, and inability to resolve complex fiber crossing [see Mori and van Zijl (13) for a technical review], it has been successfully used to model neuronal connections.

There is increasing evidence that diffusion tractography might yield reliable and reproducible results in DBS if it is performed under certain controlled conditions. Previous studies have evaluated the impact of integrating diffusion tractography-based studies in DBS, but these articles were mainly focused on the concept of diffusion tractography, technical considerations of diffusion methodologies or utility of diffusion imaging in target selection and optimization of electrode placement intraoperatively [for reviews, see Calabrese (14) or Torres et al. (15)]. In this study, we aim to review the available literature to evaluate the efficacy of using diffusion tractography in DBS to improve postoperative outcome.

\section{METHODS}

\section{Search Strategy}

An electronic search using PubMed up to July 2017 was performed to identify articles for inclusion using the key words "(diffusion tractography OR diffusion tensor imaging OR DTI) AND (deep brain stimulation OR DBS)." In addition, the reference lists of all selected studies were reviewed to further identify potentially relevant studies. Duplicate searches were eliminated. All studies were screened based on their titles and abstracts. Abstracts, conference presentations, editorials, reviews and expert opinions were excluded. Full text of the studies identified in the search process was used to further assess for inclusion.

\section{Selection Criteria}

Studies had to fulfill the following criteria to be included: (i) Involve human participants who have undergone deep brain stimulation, (ii) DTI data were acquired pre- or postoperatively, (iii) DTI data were utilized in DBS planning, or analyzed retrospectively, (iv) postoperative clinical response outcomes for the indicated use of DBS was reported, and (v) articles in the English language. Studies which reported the side effects of DBS without reporting the clinical response for DBS were excluded. Studies which reported the same series of patients were analyzed collectively and their quantitative assessment were consolidated. If different DTI analytic approaches were used on the same group of patients, these assessments were separately analyzed.

A total of 159 studies were identified through PubMed electronic search and from analysis of reference lists. After exclusion of duplicate or irrelevant references, 86 potentially relevant full text articles were retrieved for detailed evaluation. Of those articles, 35 studies met the inclusion criteria and were included in this review (Figure 1).

The studies were categorized according to their indications for DBS, DTI analysis approach, fiber tractography method, and whether these were retrospective or prospective studies. The indications for DBS included tremor, dystonia and freezing of gait for movement disorders, depression and obsessive-compulsion for psychiatric disorders, as well as various pain disorders. The two types of DTI analytical approaches have been described by Calabrese (14). Briefly, in tract stimulation modeling, the region surrounding an implanted DBS electrode was used as a seed for diffusion tractography to identify the population of brain connections which are likely to be modulated by a given DBS contact. In tract proximity analysis, the location of DBS contact was analyzed with a priori knowledge of a tract of interest to investigate whether its proximity with an electrode contact is correlated with treatment efficacy or to evaluate the accuracy of electrode targeting. Both approaches are retrospective in nature, contrary to direct tract targeting where DBS electrodes are targeted prospectively based on diffusion tractography-derived tracts of interest. Similarly, two categories of tractography methods were commonly used and include probabilistic or deterministic fiber tracking. Briefly, in deterministic tracking, the principal direction is followed bidirectionally from a seed point to generate the same set of tracts each time and assumes a dominant fiber orientation in each voxel. In the more computationally expensive and iterative method of probabilistic tracking, the full spherical function is used to estimate the probability distribution of fiber orientations. The probability is defined in a number of ways based on the algorithm used and this probability governs the reconstruction of the fasciculi. The advantages and technical limitations of these methods in DBS have been discussed extensively in existing literature [see Calabrese (14) for a recent review].

The classification of patients into responder or non-responder groups was based on their original classifications in the studies. Responder rate within each indication was calculated across all studies by dividing the total number of responders over the total sample size. Reported improvement in measures appropriate for assessing the specific symptoms indicated for DBS was used to calculate the percentage mean improvement for each study. In studies where more than one measure was reported, the data from the measure demonstrating the greatest improvement were used in the calculation for overall mean improvement. Overall percentage mean improvement within each indication was calculated by averaging the mean improvements across all studies. 


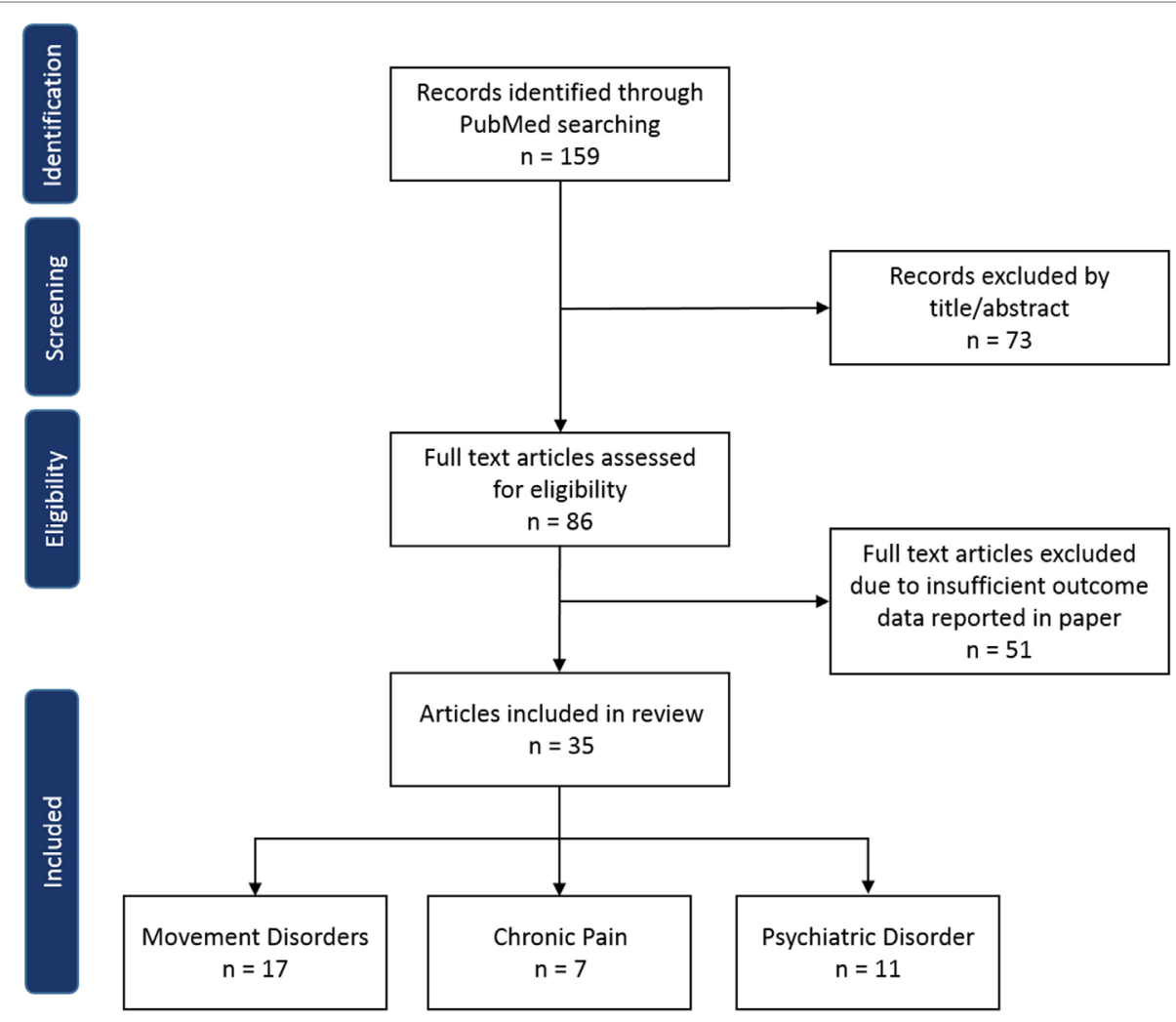

FIGURE 1 | Flow diagram of literature review.

\section{RESULTS}

\section{Overview}

Publications involving the use of DTI in DBS have increased steadily over the past 10 years, with a surge in numbers observed in 2016 (Figure 2). The studies included in this review can be found in Table 1. Out of the 35 studies, 17 (49\%) were for medically refractory movement disorders, 3 (9\%) for OCDs, 8 (23\%) for depression, and 7 (20\%) for chronic pain.

\section{Movement Disorders}

A total of 80 patients with movement disorders were treated using DBS combined with a DTI-based approach leading to an overall mean percentage improvement in symptoms of $68.7 \%$ $(\mathrm{SD}=16.0 \%)$. The main indication for DBS was medically refractory tremor (14 studies, $n=69$ ) mainly due to either Parkinson's disease or essential tremor, followed by gait dysfunction (one study, $n=1$ ) and dystonia (two studies, $n=10$ ).

\section{Medically Refractory Tremor}

Deep brain stimulation achieved an overall mean improvement of $70.0 \%(\mathrm{SD}=16.5 \%)$ over a follow-up of 11.8 months $(\mathrm{SD}=6.5)$ in 14 studies with a total of 69 patients (mean age $62.5 \pm 7.4$ years) with treatment refractory tremor (Table 2).

In six prospective studies, 27 patients underwent DBS of the ventral intermediate thalamic nucleus (VIM) (16-21), subthalamic nuclei (STN) (19), or caudal zona incerta (cZI) (18)

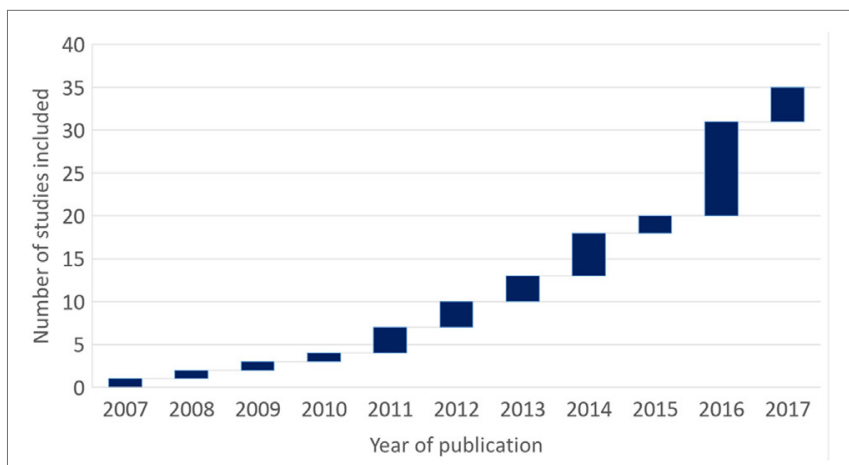

FIGURE 2 | Waterfall diagram of studies included in this review by year of publication over a decade.

(Table 2) where the dentatorubrothalamic (DRT) tract was simultaneously targeted using DTI and verified with imaging analyses postoperatively. All patients had good response (100\% responders) with a mean improvement of $71.7 \%(\mathrm{SD}=17.9 \%)$ over a follow-up period of 13.6 months $(S D=9.5)$. One patient who achieved $37.5 \%$ moderate improvement in the UPDRS-III demonstrated more than $90 \%$ reduction in baseline tremor by 6 months postoperatively (19). Another patient experienced excellent head tremor control (>90\%) which was not well represented by $18 \%$ improvement based on ETRS scores (21). 
TABLE 1 | List of studies included in this review $(N=35)$.

\begin{tabular}{|c|c|c|c|c|c|c|}
\hline First author, year (ref) & $N$ & Indication & Age (years) ${ }^{a}$ & Approach & Method & Follow-up (months) \\
\hline Fenoy, 2017 (16) & 20 & Tre $(E T)$ & $66.8 \pm 10.5$ & DTT & $\mathrm{D}$ & n.r. \\
\hline Coenen, 2017 (17) & 1 & Tre (ET) & 72 & DTT & $\mathrm{D}$ & n.r. \\
\hline O’Holloran, 2016 (18) & 2 & Tre (PD) & $63.0 \pm 2.8$ & DTT & $\mathrm{P}$ & 24 \\
\hline Coenen, 2016 (19) & 2 & Tre (PD) & $75.5 \pm 0.7$ & DTT & $\mathrm{D}$ & $5-8$ \\
\hline Coenen, 2012 (20) & 1 & Tre (ET) & 73 & $\mathrm{DTT}$ & $\mathrm{D}$ & 18 \\
\hline Coenen, 2011a (21) & 1 & Tre (Dys) & 37 & DTT & $\mathrm{D}$ & 3 \\
\hline King, 2016 (22) and Sammartino, 2016 (23) & $6^{b}$ & Tre (ET/PD) & $71.9 \pm 5.9$ & TPA & $\mathrm{P}$ & 12 \\
\hline Coenen, 2014 (24) & $9^{c}$ & Tre (ET/PD/Dys) & $64.2 \pm 17.1$ & TPA & $\mathrm{D}$ & $3-17$ \\
\hline Sweet, 2014 (25) & $7^{\mathrm{d}}$ & Tre (PD) & $62.9 \pm 7.3$ & TPA & $\mathrm{D}$ & n.r. \\
\hline Coenen, 2011b (26) & 1 & Tre (PD) & 73 & TPA & D & 6 \\
\hline Boccard, 2016a (27) & 1 & Tre (post HI) & 20 & TSM & $\mathrm{P}$ & 6 \\
\hline Klein, 2012 (28) & 12 & Tre (ET/PD) & $64.8 \pm 11.0$ & TSM & $\mathrm{P}$ & $1-3$ \\
\hline Pouratian, 2011 (29) & 6 & Tre $(E T)$ & $69.3 \pm 6.1$ & TSM & $\mathrm{P}$ & n.r. \\
\hline Schweder, 2010 (30) & 1 & $\mathrm{FOG}(\mathrm{PD})$ & 56 & TSM & $\mathrm{P}$ & n.r. \\
\hline Rozanski, 2014 (31) and Rozanski, 2017 (32) & 10 & Dys & $59.1 \pm 13.7$ & TSM & $P$ & $2-4$ \\
\hline Coenen, 2016 (33) & 2 & OCD & $41.5 \pm 13.5$ & DTT & $\mathrm{D}$ & 12 \\
\hline Makris, 2016 (34) & 1 & OCD & 30 & TPA & $\mathrm{P}$ & 6 \\
\hline Hartmann, 2016 (35) & 6 & OCD & $36.2 \pm 8.6$ & TSM & $\mathrm{P}$ & 24 \\
\hline Fenoy, 2016 (36) & 4 & Dep & $46.3 \pm 8.9$ & DTT & $\mathrm{D}$ & 4.5 \\
\hline Schlaepfer, 2013 (37) & 7 & Dep & $42.6 \pm 9.8$ & DTT & $\mathrm{P}$ & 3 \\
\hline Tsolaki, 2017 (38) & 2 & Dep & n.r. & TPA & $\mathrm{P}$ & n.r. \\
\hline McNab, 2009 (39) & 1 & Dep & 60 & TSM & D & 12 \\
\hline Accolla, 2016 (40) & 5 & Dep & $45.2 \pm 14.4$ & TSM & $\mathrm{D}$ & 6 \\
\hline Riva-Posse, 2014 (41) & 14 & Dep & $42.0 \pm 8.9$ & TSM & $\mathrm{P}$ & 24 \\
\hline Lujan, 2013 (42) & 1 & Dep & n.r. & TSM & $\mathrm{P}$ & 12 \\
\hline Lujan, 2012 (43) & 7 & Dep & $42.4 \pm 13.3$ & TSM & D & $15-41$ \\
\hline Coenen, 2015 (44) & 1 & Pain & n.r. & DTT & $\mathrm{D}$ & 15 \\
\hline Hunsche, 2013 (45) & 4 & Pain & $60.8 \pm 13.6$ & DTT & $\mathrm{D}$ & 12 \\
\hline Boccard, 2016b (46) & 8 & Pain & $53.4 \pm 6.0$ & TSM & $\mathrm{P}$ & n.r. \\
\hline Kim, 2016 (47) & 5 & Pain & $56.0 \pm 14.8$ & TSM & $\mathrm{P}$ & $2-48$ \\
\hline Kovanliyaka, 2014 (48) & 1 & Pain & 44 & TSM & $\mathrm{D}$ & 12 \\
\hline Owen, 2007 (49) and Owen, 2008 (50) & 4 & Pain & n.r. & TSM & $P$ & n.r. \\
\hline
\end{tabular}

n.r., not reported.

Indications. Tre, tremor; PD, Parkinson's disease; ET, essential tremor; Dys, dystonia; HI, head injury; FOG, freezing of gait;

$\mathrm{OCD}$, obsessive-compulsive disorder; Dep, depression.

Approaches. DTT, direct tract targeting; TPA, tract proximity analysis; TSM, tract stimulation modeling.

Methods. $D$, deterministic; $P$, probabilistic.

${ }^{a}$ Ages are expressed as mean $\pm S D$.

${ }^{b}$ Two underwent DBS while four had thalatomy.

${ }^{c}$ Excluded two patients who also appeared in the study by Coenen et al. (20) and Coenen et al. (21).

${ }^{d}$ Excluded two patients who did not have tremor symptoms preoperatively.

In eight studies (22-30) where DTI was used in post hoc analysis, the overall mean improvement with DBS was $68.5 \%$ $(\mathrm{SD}=15.7 \%)$ over a mean follow-up period of 8.8 months ( $\mathrm{SD}=3.1$ ), with 38 out of 42 patients $(90 \%)$ achieving good response (Table 2). The overall mean improvement between responders and non-responders were $73.1 \%(\mathrm{SD}=11.6 \%)$ and $31.0 \%(\mathrm{SD}=13.2 \%)$, respectively. The responder rate was therefore higher in the prospective DTI group (100\%) compared to the retrospective DTI group (90\%).

Diffusion tensor imaging was used in the post hoc analysis of the DRT tract proximity to the implanted electrode contacts in five studies with 25 patients who underwent stimulation of the VIM or STN (22-26). Analysis of electrode proximity to the DRT tract found that effective electrodes were localized in close proximity of or within the DRT tract itself among the good responders, with an optimal position of the active contact located just anterior to or at the center of the DRT (24). There was a non-significant trend toward improved efficacy with increasing proximity of the DRT tract and the electrode contact or stimulated electrical fields $(24,25)$. Ineffective contacts tended to be located outside the anterior border of the DRT tract and further from the center (3 vs. $1.97 \mathrm{~mm}$ ) (24). Postoperative tremor control tended to be better when the DRT was closer to the volume of tissue activated by the effective contact (25).

Differences in connectivity patterns of effective and noneffective electrode contacts to the cortical and subcortical areas were analyzed among 19 patients in another four studies (27-29). Effective contacts for tremor control were found to have stronger structural connectivity to the superior frontal gyrus in Parkinson's disease patients (27) and primary motor cortex in essential tremor patients $(28,29)$. Klein et al. $(28)$ observed in 12 patients with tremor that there was a smaller volume of precentral gyrus connectivity with ineffective electrodes compared to effective electrodes, and consequently a weaker structural connectivity to the premotor cortex. 
TABLE 2 | Deep brain stimulation with diffusion tensor imaging for tremor.

\begin{tabular}{|c|c|c|c|c|c|c|}
\hline First author (ref) & Response & Scale & Mean preop, score (range) & $\begin{array}{c}\text { Mean postop, score } \\
\text { (range) }\end{array}$ & $\begin{array}{c}\text { Mean improvement } \\
(\%)\end{array}$ & Target \\
\hline \multicolumn{7}{|c|}{ Prospective direct tract targeting } \\
\hline \multirow[t]{3}{*}{ Fenoy (16) } & 20 responders & TETRAS (head) & $2.3 \pm 0.5(2-3)$ & $0.8 \pm 0.4(0-1)$ & $63.9 \pm 19.5$ & VIM \\
\hline & & TETRAS (right arm) & $2.6 \pm 0.5(2-3.5)$ & $0.8 \pm 0.5(0-1.5)$ & $71.7 \pm 18.4$ & \\
\hline & & TETRAS (left arm) & $2.7 \pm 0.5(2-4)$ & $0.8 \pm 0.6(0-1.5)$ & $71.9 \pm 20.6$ & \\
\hline Coenen (17) & 1 responder & ETRS & 51 & 20 & 61 & VIM \\
\hline O’Halloran (18) & 2 responders & UPDRS-III global & $41.0 \pm 46.7(8-74)$ & $8.5 \pm 5.0(5-12)$ & $60.6 \pm 32.5$ & $\left.c Z\right|^{a}$ \\
\hline \multirow[t]{2}{*}{ Coenen (19) } & 2 responders & UPDRS-III global & $59.5 \pm 5.0(56-63)$ & Both 11 & $81.4 \pm 1.5$ & STN \\
\hline & & UPDRS-III tremor & $13.5 \pm 3.5(11-16)$ & $2.5 \pm 0.7(2-3)$ & $81.5 \pm 0.4$ & \\
\hline Coenen (20) & 1 responder & ETRS & 63 & 22 & 65 & VIM \\
\hline \multirow[t]{2}{*}{ Coenen (21) } & 1 responder $^{b}$ & ETRS & 11 & 9 & 18 & VIM \\
\hline & & Head tremor & & & 90 & \\
\hline
\end{tabular}

\section{Retrospective tract proximity analyses}

\begin{tabular}{|c|c|c|c|c|c|c|}
\hline King (22)/Sammartino (23) & 6 responders & $\begin{array}{l}\text { CRST B } \\
\text { TETRAS }\end{array}$ & $\begin{array}{c}19.2 \pm 5.7(11-28) \\
17.8 \pm 5.4\end{array}$ & $7.8 \pm 2.6(5-11)$ & $\begin{array}{c}56.9 \pm 15.5 \\
56.0 \pm 11.9 \text { (overall) } \\
78.0 \pm 17.2 \text { (op side) }\end{array}$ & VIM \\
\hline Coenen (24) & $\begin{array}{l}8 \text { responders } \\
1^{\mathrm{C}} \text { non-responder }\end{array}$ & CRST & $\begin{array}{c}49.6 \pm 12.8(36-68) \\
35\end{array}$ & $\begin{array}{c}12.4 \pm 7.4(3-23) \\
21\end{array}$ & $\begin{array}{c}76.7 \pm 10.9 \\
40.0\end{array}$ & VIM \\
\hline Sweet (25) & $\begin{array}{l}4^{d} \text { responders } \\
3 \text { non-responders }\end{array}$ & UPDRS-III tremor & $\begin{array}{c}8.2 \pm 3.1(5.5-11.5) \\
7.5 \pm 4.2(3-13)\end{array}$ & $\begin{array}{l}6.3 \pm 2.1(4-8) \\
1.1 \pm 1.4(0-3)\end{array}$ & $\begin{array}{l}87.8 \pm 17.4 \\
21.3 \pm 12.5\end{array}$ & STN \\
\hline Coenen (26) & 1 responder & $\begin{array}{l}\text { ETRS } \\
\text { UPDRS-III global } \\
\text { UPDRS-III tremor }\end{array}$ & $\begin{array}{c}33 \\
27 \\
7\end{array}$ & $\begin{array}{c}9 \\
17 \\
1\end{array}$ & $\begin{array}{c}72.7 \\
37.0 \text { (stopped meds) } \\
85.7 \text { (stopped meds) }\end{array}$ & VIM \\
\hline \multicolumn{7}{|c|}{ Retrospective tract stimulation modeling } \\
\hline $\begin{array}{l}\text { Boccard (27) } \\
\text { Klein (28) } \\
\text { Pouratian (29) }\end{array}$ & $\begin{array}{l}1 \text { responder } \\
12 \text { responder } \\
6 \text { responder }\end{array}$ & $\begin{array}{l}\text { CRST } \\
\text { FTM A + B } \\
\text { FTM global } \\
\text { FTM A } \\
\text { FTM B }\end{array}$ & $\begin{array}{c}25 \\
46.2 \pm 16.5(18-77) \\
53.7 \pm 24.0(9-73) \\
10.0 \pm 6.3(2-19) \\
5.4 \pm 2.7(2-10)\end{array}$ & $\begin{array}{c}7 \\
13.6 \pm 8.6(3-33) \\
32.8 \pm 24.0(9-66) \\
5.9 \pm 4.5(0-15) \\
2.1 \pm 1.4(0-4)\end{array}$ & $\begin{array}{c}72.0 \\
71.8 \pm 11.8 \\
39.0 \\
41.0 \\
61.0\end{array}$ & $\begin{array}{l}\text { VOP-ZI } \\
\text { VIM } \\
\text { VIM }\end{array}$ \\
\hline
\end{tabular}

Prospective cohort:

Overall responder proportion $=27$ out of $27(100 \%)$

Overall mean improvement in responders $=71.7 \pm 17.9 \%$

Overall mean improvement among non-responders $=$ nil

Retrospective cohort:

Overall responder proportion $=38$ out of $42(90 \%)$

Overall mean improvement in responders $=73.1 \pm 11.6 \%$

Overall mean improvement among non-responders $=31.0 \pm 13.2 \%$

Scales. TETRAS, The Essential Tremor Rating Assessment Scale (51); ETRS, Essential Tremor Rating Scale; UPDRS-III, Unified Parkinson's Disease Rating Scale part III measures motor signs of PD (52); CRST, clinical rating scale for tremor (53); FTM, Fahn-Tolosa-Marin tremor rating scale (54); FTM A measures tremor severity; FTM B measures task-related tremor.

Targets. cZI, caudal zona incerta; STN, subthalamic nucleus; VIM, ventral intermediate thalamus; VOP-ZI, ventral oral posterior thalamic nucleus-zona incerta.

a One patient had initial right-sided lead implanted within cZl, but the DRT (with an atypical anterior trajectory) was outside of field of stimulation. Patient experienced stimulation-

induced dystonic symptoms and the lead was replaced with one implanted in a more anterior position within DRT, giving good tremor relief with reduced side effects.

${ }^{b}$ Patient demonstrated excellent head tremor control (>90\%) which was not well expressed by $18 \%$ improvement in ETRS.

"Patient showed $42 \%$ improvement in ETRS but had complicated ET with "yes-yes"-type of head tremor which was hard to judge intraoperatively.

${ }^{d}$ Excluded two patients who did not have tremor symptoms preoperatively.

\section{Gait Dysfunction in Parkinson's Disease}

In a single patient study for Parkinson's disease-related on-state freezing of gait, DBS was performed with direct targeting of the pedunculopontine nucleus (PPN) with the aid of DTI FA mapping (30). The patient demonstrated $42 \%$ improvement in a freezing of gait questionnaire score and 14\% improvement in the gait and falls questionnaire postoperatively. Comparison of pre- and post-DBS imaging revealed a normalization effect on pathological PPN connectivity with DBS. In particular, loss of pre-DBS cerebellar connectivity was restored, while overactivity of the corticopontine fibers in the anterior pons was reduced postoperatively. Additionally, dominant connectivity with motor cortex observed pre-DBS was reduced and connectivity with other prefrontal areas such as the primary motor cortex became dominant postoperatively. The authors suggest that DBS may affect reorganization in the topography of connectivity and neuroplasticity.

\section{Medically Refractory Dystonia}

Deep brain stimulation of the globus pallidus internus (GPi) in 10 patients (mean age $59.1 \pm 14$ years) with medically intractable dystonia achieved excellent response in all patients, with an overall mean improvement of $79.5 \%(\mathrm{SD}=12.0 \%)$ on the BurkeFahn-Marsden Dystonia Rating Scale, part II subscale $(31,32)$ over a follow-up period between 2 and 4 months. Retrospective DTI analysis (31) revealed that clinically effective ventral GPi electrodes had stronger connectivity to posterior cortical areas in the primary sensory cortex and posterior motor cortical regions, while dorsal GPi (less clinically efficient) were more connected to anterior cortex in motor and premotor regions. Rozanski 
et al. (32) extended their work in the same group of patients by showing a close anatomic vicinity of the clinically efficient DBS electrodes and the pallidothalamic tract, in particular the ansa lenticularis, providing support for the pallidothalamic tracts as DBS target for dystonia.

\section{Medically Refractory OCD}

In three studies with nine patients (mean age $36.7 \pm 9.0$ years) with treatment refractory OCD, DBS achieved an overall mean reduction of $36.5 \%$ ( $\mathrm{SD}=19.1 \%)$ on the Yale-Brown ObsessiveCompulsive Scale (Y-BOCS) over a mean follow-up period of 19.3 months (SD = 7.2) (33-35) (Table 3).

Deep brain stimulation of the anterior limb of the internal capsule (ventral capsule) and ventral striatum (VC/VS) was performed in two patients with simultaneous targeting of the superolateral branch of the medial forebrain bundle (slMFB) with the aid of DTI (33). Both patients showed good response with a mean improvement of $41.7 \%(\mathrm{SD}=11.8 \%)$ at 12 months.

In two studies $(34,35)$ where DTI was used in post hoc analysis, the overall mean improvement with DBS was $34.8 \%$ $(\mathrm{SD}=22.7 \%)$ over a mean follow-up period of 21.4 months $(\mathrm{SD}=6.8)$, with five out of seven patients $(71 \%)$ achieving good response. The overall mean improvement among responders and non-responders were $44.4 \%(\mathrm{SD}=27.9 \%)$ and $15.8 \%$ $(\mathrm{SD}=17.5 \%)$, respectively.

Retrospective tract proximity analysis was performed for a patient who underwent DBS of the VC/VS with $34.8 \%$ reduction in Y-BOCS (34). The study found that ineffective contacts only engage either one or none of the lateral or medial orbitofrontal cortex-thalamic connecting tracts. The authors proposed a tractography-guided patient-specific approach in DBS targeting the "center of mass" of orbitofrontal cortex-thalamic connections.

Computational models were used to stimulate the activation of fiber tracts by the DBS electrodes in six patients who underwent DBS of the anterior limb of the internal capsule and nucleus accumbens (35). Large fiber activation were observed in the right middle (anterior part) frontal gyrus in patients with best response (mean improvement 77\%), superior frontal gyrus in the moderate responders (mean improvement 30.5\%) and right thalamus and orbital part of the inferior frontal gyrus in the non-responders (mean improvement $\leq 5 \%$ ).

\section{Medically Refractory Depression}

Deep brain stimulation for treatment refractory depression achieved an overall mean improvement of $48.3 \%$ (SD $=40.0 \%)$ over follow-up period of 21.1 months $(\mathrm{SD}=14.9)$ in eight studies with a total of 40 patients (mean age $46.4 \pm 11.1$ years) (36-43) (Table 4).

In prospective studies where the slMFB was directly targeted during DBS with DTI in 10 patients for treatment resistant depression, there was an overall mean improvement in MADRS of $61.6 \%$ (SD $=34.9 \%)(36,37)$. The overall improvement among responders $(n=8)$ and non-responders $(n=2)$ were $68.0 \%(\mathrm{SD}=10.0 \%)$ and $11.6 \%(\mathrm{SD}=0.2 \%)$, respectively. DTI analyses revealed that the final electrode locations were found to be in close proximity or within the slMFB among the eight responders. In one non-responder, the final electrode was localized in the slMFB but weaker connectivity was found between the MFB and the prefrontal cortex compared to the responders (36). Analysis results of the electrode location or connectivity was not reported in the remaining nonresponder (37).

In six studies (38-43) where DTI was used in post hoc analysis, the overall mean improvement with DBS was $43.0 \%$ $(\mathrm{SD}=44.0 \%)$ over a mean follow-up period of 8.8 months $(\mathrm{SD}=3.1)$, with 20 out of 30 patients $(66.7 \%)$ achieving good response (Table 4). The overall mean improvement among responders and non-responders were $83.9 \%(\mathrm{SD}=3.6 \%)$ and $8.3 \%(\mathrm{SD}=15.4 \%)$, respectively.

TABLE 3 | Deep brain stimulation with diffusion tensor imaging for obsessive-compulsive disorder.

\begin{tabular}{|c|c|c|c|c|c|c|c|}
\hline First author (ref) & Response & Scale & $\begin{array}{l}\text { Mean preop, } \\
\text { scores (range) }\end{array}$ & $\begin{array}{l}\text { Mean postop, } \\
\text { scores (range) }\end{array}$ & $\begin{array}{c}\text { Mean } \\
\text { improvement (\%) }\end{array}$ & Target & Tract \\
\hline \multicolumn{8}{|c|}{ Prospective direct tract targeting } \\
\hline \multicolumn{8}{|c|}{ Retrospective tract proximity analysis } \\
\hline Makris (34) & 1 responder & Y-BOCS & Not reported & Not reported & 35 & VC/NS & $\begin{array}{l}\text { IOFC-thal } \\
\text { mOFC-thal }\end{array}$ \\
\hline \multicolumn{8}{|c|}{ Retrospective tract stimulation modeling } \\
\hline Hartmann (35) & $\begin{array}{l}4 \text { responders } \\
2 \text { non-responders }\end{array}$ & Y-BOCS & Not reported & Not reported & $\begin{array}{l}53.8 \pm 27.9 \\
15.8 \pm 17.5\end{array}$ & ALIC NACC & - \\
\hline
\end{tabular}

Prospective cohort:

Overall responder proportion $=2$ out of $2(100 \%)$

Overall mean improvement in responders $=41.7 \pm 11.8 \%$

Overall mean improvement among non-responders $=$ n.a.
Retrospective cohort:

Overall responder proportion $=5$ out of $7(71 \%)$

Overall mean improvement in responders $=44.4 \pm 27.9 \%$

Overall mean improvement among non-responders $=15.8 \pm 17.5 \%$

Scale. Y-BOCS, Yale-Brown Obsessive-Compulsive Scale (55).

Targets. VCNS, ventral anterior internal capsule and ventral striatum; ALIC, anterior limb of internal capsule; NAcc, nucleus accumbens.

Tract. I/mOFC-thal, lateral/medial orbitofrontocortical-thalamic. 
TABLE 4 | Deep brain stimulation with diffusion tensor imaging for depression.

\begin{tabular}{|c|c|c|c|c|c|c|}
\hline First author (ref) & Response & Scale & Preop scores & Postop scores & Mean improvement (\%) & Target \\
\hline \multicolumn{7}{|c|}{ Prospective direct tract targeting } \\
\hline \multirow[t]{4}{*}{ Fenoy (36) } & $2^{\mathrm{a}}$ responders & MADRS & $32.5 \pm 3.5(30-35)$ & $5.0 \pm 1.4(4-6)$ & $84.8 \pm 2.7$ & sIMFB \\
\hline & 1 non-responder & HDRS29 & $41.5 \pm 0.7(41-42)$ & $11.0 \pm 11.3(3-19)$ & $73.7 \pm 26.8$ & \\
\hline & & MADRS & 34 & 30 & 12 & \\
\hline & & HDRS29 & 37 & 28 & 24 & \\
\hline \multirow[t]{4}{*}{ Schlaepfer (37) } & 6 responders & MADR & $29.0 \pm 8.4(15-39)$ & $7.7 \pm 4.3(2-13)$ & $71.4 \pm 17.4$ & sIMFB \\
\hline & & HDRS24 & $23.0 \pm 1.7(21-25)$ & $13.0 \pm 7.4(2-21)$ & $44.0 \pm 31.7$ & \\
\hline & 1 non-responder & MADR & 35 & 31 & 11 & \\
\hline & & HDRS24 & 23 & 25 & -9 & \\
\hline \multicolumn{7}{|c|}{ Retrospective tract stimulation modeling } \\
\hline \multirow[t]{2}{*}{ Tsolaki (38) } & 1 responder & MADRS & Not reported & Not reported & 84 & SCC \\
\hline & 1 non-responder & & Not reported & Not reported & 8 & \\
\hline McNab (39) & 1 non-responder & BDI-II & 41 & Not reported & No effect & SACC \\
\hline \multirow[t]{4}{*}{ Accolla $(40)$} & 1 responder & HAMD24 & 28 & 7 & 75.0 & Posterior gyrus rectus \\
\hline & & $\mathrm{BDI}$ & 34 & 12 & 64.7 & \\
\hline & $4^{\mathrm{b}}$ non-responders & HAMD24 & $28.8 \pm 3.6(24-32)$ & $29.0 \pm 5.7(21-33)$ & $-3.4 \pm 30.6$ & SCC \\
\hline & & $\mathrm{BDI}$ & $42.8 \pm 11.1(30-57)$ & $42.3 \pm 9.6(31-52)$ & $-1.2 \pm 9.4$ & \\
\hline \multirow[t]{2}{*}{ Riva-Posse $(41)^{c}$} & 12 responders & HDRS17 & $23.9 \pm 0.7$ & $(n=7) \mathrm{HDRS}<8$ & $>50$ & SCC \\
\hline & $2^{\mathrm{d}}$ non-responders & BDI-II & $38.4 \pm 2.1$ & $\begin{array}{c}(n=5) \mathrm{HDRS}<15 \\
\text { HDRS }>15\end{array}$ & $<50$ & \\
\hline Lujan (42) & 1 responder & HDRS17 & 23 & 5 & 78.3 & SCC \\
\hline \multirow[t]{4}{*}{ Lujan (43) } & 5 responders & HDRS & $32.0 \pm 3.5(26-35)$ & $2.6 \pm 3.6(0-9)$ & $92.0 \pm 10.7$ & VCNS \\
\hline & & MADRS & $30.6 \pm 5.3(25-37)$ & $0.6 \pm 1.3(0-3)$ & $98.4 \pm 3.6$ & \\
\hline & 2 non-responders & HDRS & $32.0 \pm 7.1(27-37)$ & $30.5 \pm 4.9(27-34)$ & $4.1 \pm 5.7$ & \\
\hline & & MADRS & $30.0 \pm 2.8(28-32)$ & $21.5 \pm 4.9(18-25)$ & $28.8 \pm 9.8$ & \\
\hline
\end{tabular}

Prospective cohort:

Overall responder proportion $=8$ out of $10(80 \%)$

Retrospective cohort:

Overall mean improvement in responders $=68.0 \pm 10.0 \%$

Overall responder proportion $=20$ out of $30(67 \%)$

Overall mean improvement among non-responders $=11.6 \pm 0.2 \%$

Overall mean improvement in responders = 83.9 $\pm 3.6 \%$

Overall mean improvement among non-responders $=8.3 \pm 15.4 \%$

Scale. MADRS, Montgomery-Asberg Depression Rating Scale (56); HDRS29/HDRS24/HDRS17/HAMD24, Hamilton Depression Rating Scale (57, 58); BDI/BDI-II, Beck Depression Inventory $(59,60)$.

Targets. SCC, subcallosal cingulate cortex; VCNS, ventral capsule/ventral striatum; SACC, subgenual anterior cingulate cortex.

${ }^{a}$ Excluded one patient who withdrew before follow-up at 26 weeks. MADRS scores at postop 1 week showed 51\% improvement.

${ }^{b}$ Two requested for removal of DBS system within 12 months.

${ }^{\circ}$ Outcomes were referenced from Holtzheimer et al. (61).

${ }^{d}$ Two patients were explanted before 24 months.

Differences in connectivity patterns of electrode contacts to cortical and subcortical areas were analyzed in 30 patients (37-43). DBS of the subgenual anterior cingulate cortex did not lead to any therapeutic effect in a single patient study (39). DTI analyses in the non-responder revealed that connectivity in amygdalar-thalamic and amygdalar-SACC was found to be disrupted.

In three studies, retrospective analyses of the connectivity of DBS electrode to cortical regions were performed in 19 patients who underwent DBS of the subcallosal cingulate (40-42). Higher connectivity in the medial prefontal areas and ventral caudate was observed while lower connectivity to middle and posterior cingulate were observed in the patient with good response who underwent DBS in the posterior gyrus rectus was compared to four non-responders who had DBS in the subcallosal cingulate (40). Common pathways connecting the medial frontal cortex, cingulate cortex and subcortical nuclei was seen in responders, but not in non-responders (41). In a good responder, the number of axons within the same pathway activated by the effective electrode, which produced the best therapeutic effects, was significantly higher than the sub-therapeutic electrode contacts (42). Tsolaki et al. (38) used tractography to identify the optimal site of stimulation within the subcallosal cingulate cortex, and further demonstrated that compared to non-responder, the DBS electrodes in the responder were implanted and stimulation delivered closer to the tractography-optimized target.

\section{Medically Refractory Pain Disorders}

A total of 23 patients (mean age $55.2 \pm 10.7$ years) in seven studies underwent DBS for chronic pain (44-50) (Table 5) with an overall improvement of $49.7 \%$ ( $S D=35.1 \%$ ).

Diffusion tensor imaging was used prospectively to target white matter tracts of interest in five patients $(44,45)$ a mean improvement was $42.8 \%$ ( $S D=23.1 \%)$ with four out of five $(80 \%)$ achieving good response. The mean improvement in responders and non-responder are $51.7 \pm 23.1$ and $25 \%$, respectively.

In a single patient study where DBS to periventricular/ periaqueductal gray (PVG/PAG) was performed, DTI was used to target the median polysynaptic pain system and trigeminal 
TABLE 5 | Deep brain stimulation with diffusion tensor imaging for pain disorders.

\begin{tabular}{|c|c|c|c|c|c|c|c|}
\hline First author (ref) & Response & Scale & Preop scores & Postop scores & Mean improvement (\%) & Target & Tract \\
\hline \multicolumn{8}{|c|}{ Prospective direct tract targeting } \\
\hline Coenen (44) & 1 responder & VAS & $7-9$ & $2-5$ & $44-78$ & PVG, PAG, VCP & $\begin{array}{c}\text { MPNS/ATR IC/ } \\
\text { STP } \\
\text { TL/ML }\end{array}$ \\
\hline Hunsche (45) & $\begin{array}{l}3 \text { responders } \\
1 \text { non-responder }\end{array}$ & VAS & All 10 & $\begin{array}{c}4.7 \pm 2.3(2-6) \\
9\end{array}$ & $\begin{array}{c}53.3 \pm 23.1 \\
10\end{array}$ & PLIC & STC \\
\hline \multicolumn{8}{|c|}{ Retrospective tract stimulation modeling } \\
\hline Boccard (46) & 6 responders & VAS & $8.4 \pm 1.4(6-10)$ & Not reported & $\begin{array}{l}\text { Analgesic relief in all, with } 1 \text { pain } \\
\text { free }\end{array}$ & ACC & - \\
\hline & $2^{\mathrm{a}}$ non-responders & & $9-10$ & Not reported & - & & \\
\hline Kim (47) & $\begin{array}{l}4 \text { responders } \\
1 \text { non-responder }\end{array}$ & VAS & Not reported & Not reported & $\begin{array}{l}\text { Moderate to significant } \\
\text { No relief }\end{array}$ & PAG, VPL, VPM & - \\
\hline Kovanliyaka (48) & 1 responder & - & - & Pain free & 100 & VPL & - \\
\hline Owen $(49,50)$ & $\begin{array}{l}2 \text { responders } \\
2^{\mathrm{b}} \text { non-responders }\end{array}$ & $\mathrm{MPQ}$ & $\begin{array}{l}20.0 \pm 12.7(11-29) \\
41.5 \pm 19.1(55-28)\end{array}$ & $\begin{array}{l}\text { Both } 0 \\
\text { 43, explanted }\end{array}$ & $\begin{array}{c}100 \\
22\end{array}$ & PVG, PAG & - \\
\hline
\end{tabular}

Prospective cohort:

Overall responder proportion $=4$ out of $5(80 \%)$

Overall mean improvement in responders $=51.7 \pm 23.1 \%$

Overall mean improvement among non-responders $=25.0 \%$

Retrospective cohort:

Overall responder proportion $=13$ out of $18(72 \%)$

(Insufficient quantitative data to calculate overall mean improvement)

Scales. VAS, visual analog scale; MPQ, McGill Pain Questionnaire (62).

Targets. PVG, periventricular gray; PAG, periaqueductal gray; VCP, nucleus ventralis caudalis posterior; PLIC, posterior limp of internal capsule;

ACC, anterior cingulate cortex; VPL, ventroposterolateral nucleus; VPM, ventroposteromedial nucleus.

Tracts. MPNS/ATR, median polysynaptic pain system/anterior thalamic radiation; IC/STP, internal capsule/superior thalamic peduncle; TL/ML,

trigeminal lemniscus/medial meniscus; STC, spinothalamocortical tract.

ane patient requested for DBS system removed and one did not have the internal pulse generator implanted.

${ }^{b}$ System was explanted in one patient (non-responder) after trial due to poor efficacy.

lemniscus/medial lemniscus (44). The final electrode position was verified postoperatively and the patient had good pain relief postoperatively. In another four patients, DTI was used for targeting of the spinothalamocortical tract in addition to the posterior limb of internal capsule (45). Only three reported good pain relief while stimulation failed to reach any longlasting positive effects for one patient. Postoperative imaging showed the electrodes localized in the intended locations in all patients and reconstruction of the spinothalamocortical tract did not reveal any differences between the non-responder and other responders in terms of electrode location (45).

Diffusion tensor imaging was used in the retrospective analyses of the electrode connectivity to remote brain regions (46-50), with 13 out of 18 patients (72\%) achieving good response. In a group of eight patients where the anterior cingulate cortex (ACC) was stimulated, DTI analyses showed responders ( $n=6)$ had stronger connectivity to the anterior thalamus and brain stem (through the medial forebrain bundle/anterior thalamic radiation), insula, and superior middle frontal gyrus while non-responders $(n=2)$ had stronger connectivity to the precuneus and cingulum (46).

Periventricular gray/PAG was targeted in eight patients (six responders), among whom four also received simultaneous stimulation in the ventroposterolateral and ventroposteromedial nuclei (VPL/VPM) $(47,49,50)$. Those with suboptimal outcomes (one non-responder and one responder who subsequently failed) had electrodes which were found to be too medial to the VPL/VPM region (47).

\section{DTI Use in Revision Surgery}

Further evidence for tractography-based DBS surgery have been found in cases where revision or removal of an initially implanted leads using conventional methods led to the electrode location or stimulation being outside the DRT. Revision of electrodes based on direct tract targeting of the DRT tract resulted in improved efficacy of more than 50\%. For instance, O'Halloran et al. (18) reported a 61-year-old patient who underwent bilateral DBS of cZI. He experienced good initial response (>90\%) but subsequently developed dystonia of left leg and speech slurring. Tract proximity analyses showed a right-sided lead slightly posterior to DRT tract (but still well within cZI). The right DRT tract had an atypical anterior trajectory and was located outside the field of stimulation of the DRT tract. The lead was revised to a more anterior location within the field of stimulation and closer to the STN, leading to $84 \%$ improvement in tremor control without complication.

Coenen et al. (19) reported a 75-year-old patient with equivalent-type idiopathic Parkinson's syndrome who underwent bilateral DBS to STN performed using the conventional approach. He experienced overall symptoms improvement of $54 \%$ but was unsatisfied with the extent of right upper extremity tremor reduction. Tract proximity analysis revealed the electrode tip was in close proximity but barely touching the DRT tract. The system was subsequently explanted 2 months later due to infection and a second implantation was performed with a parietal approach. The newly placed 
electrode localized in and stimulated both DRT tract and STN simultaneously, leading to $62 \%$ improvement in UPDRS-III, $78 \%$ improvement in tremor, and $70 \%$ marked reduction of medication.

In another case report, a 73-year-old woman with essential tremor initially underwent bilateral thalamic DBS of the VIM with conventional targeting methods and intraoperative test stimulation (20). Monolopar stimulation was insufficient for left sided tremor control and a change to bipolar stimulation led to moderate tremor control with stimulation induced gait instability. She underwent a second surgery to have additional right-sided electrode implantation aimed directly at the DRT tract. Combined stimulation of both right sided electrodes led to sufficient $65 \%$ tremor control.

Coenen et al. (17) reported a patient with proximal and trunkal "yes-yes" - tremor who underwent conventional bilateral DBS of the VIM and experienced initial beneficial effects. Tremor reoccurred after the microlesioning effect subsided and there was no marked improvement with adjustments over time. The electrodes were explanted. He underwent DTI-assisted DBS revision surgery targeting the DRT in the subthalamic region and showed immediate and sustained improvement of $61 \%$ up to 1 year. Analysis of cortical connections revealed both implantations involved the DRT but had different patterns of fiber projections. The initial DBS showed less selective activation of fibers projecting to dorsal prefrontal and supplementary motor region (more anterior and medial). The electrodes in the second implantation revealed more lateral and posterior projections and greater involvement of the precentral and postcentral gyrus.

A patient who presented with neuropathic trigeminal pain syndrome after repeated resection of an epidermoid tumor involving the trigeminal ganglion was reported by Coenen et al. (44). The patient had DBS to the PV/PAG and sensory thalamus which did not provide pain relief clinically (VAS 7-9). The previously implanted electrodes were seen touching the median polysynaptic pain system on MR imaging and subsequently explanted. New DBS electrodes were implanted in the PV/PAG and VCP, and diffusion tractography revealed they stimulated both the lateral and medial (internal capsule/superior thalamic peduncle and trigeminal and medial lemniscus) systems, leading to good outcome (VAS 2-5) over 15 months.

\section{DISCUSSION}

Although majority of the studies of earlier studies were retrospective in nature and have provided a strong basis for the utility of integrating diffusion tractography into DBS planning. More recent studies have used DTI prospectively and have tended to show a greater response rate compared to the retrospective studies. These reported improved response rates have been more apparent in studies of essential tremor and depression.

In the retrospective studies, patients in whom the DBS electrodes were within the DTI targets based on tract proximity analysis experienced better outcomes than those in whom the electrodes were not. Case series of unsuccessful direct tract targeting in essential tremor and Parkinson's disease patients, for instance, have shown electrodes implanted using the conventional approach and found outside of the DRT tract had unsatisfactory efficacy. Lead revision of these electrodes or additional electrode implantation targeted at DRT tract prospectively consistently led to significantly improved tremor control (17-20). In such cases which are in effect direct comparison between conventional versus DTI-based targeting, the DTI-based approach appeared to provide better outcome.

In other cases, the electrode was localized in the putative correct position but stimulation did not lead to expected efficacy. Tract stimulation modeling revealed that there were significant differences in connectivity to specific cortical and subcortical areas (36). Beyond accurate targeting of the structures and white matter tracts, DTI can be used to evaluate white matter connectivity between putative targets and subcortical or cortical areas as these appear to have a significant importance in determining good outcome. Analysis of this structural connectivity could inform preoperative decision making and potentially predict treatment outcomes.

Our review show that the most commonly used method in prospective studies for surgical planning was based on the deterministic algorithm. The use of probabilistic tractography was mainly used for tract proximity or simulation in retrospective studies. In the article by Sammartino et al. (23), a comparison was performed comparing deterministic against probabilistic tractography for the DRT in six patients with essential tremor. The authors report equivalent results using either probabilistic or deterministic techniques. The higher structural connectivity obtained through probabilistic tracking did not translate into more accurate target definition of the VIM over the deterministic method. Therefore, for certain well-known tracts such as the slMFB or DRT, it would appear that the deterministic tractography using currently commercially available software would be sufficient for target definition without having to use the more computationally and time intensive probabilistic method.

Many of the current studies are limited by their small sample size or retrospective nature. However, it would appear that DTI has utility in patient-specific anatomical targeting that can be used to increase the efficacy of DBS surgery. Furthermore, connectivity studies can also be used to predict outcome from DBS surgery. More recent prospective studies are also showing increased response rates compared to the initial retrospective studies. The use of DTI in DBS planning appears to be underutilized and further studies are warranted given that surgical outcome can be optimized using this non-invasive technique.

\section{AUTHOR CONTRIBUTIONS}

All authors have made a substantial, direct, and intellectual contribution to the work and approved it for publication. 


\section{REFERENCES}

1. Kleiner-Fisman G, Herzog J, Fisman DN, Tamma F, Lyons KE, Pahwa R, et al. Subthalamic nucleus deep brain stimulation: summary and metaanalysis of outcomes. Mov Disord (2006) 21(S14):S290-304. doi:10.1002/ mds. 20962

2. Weaver FM, Follett K, Stern M, Hur K, Harris C, Marks WJ, et al. Bilateral deep brain stimulation vs best medical therapy for patients with advanced Parkinson disease: a randomized controlled trial. JAMA (2009) 301(1):63-73. doi:10.1001/jama.2008.929

3. Bronstein JM, Tagliati M, Alterman RL, Lozano AM, Volkmann J, Stefani A, et al. Deep brain stimulation for Parkinson disease: an expert consensus and review of key issues. Arch Neurol (2011) 68(2):165. doi:10.1001/ archneurol.2010.260

4. Flora ED, Perera CL, Cameron AL, Maddern GJ. Deep brain stimulation for essential tremor: a systematic review. Mov Disord (2010) 25(11):1550-9. doi:10.1002/mds. 23195

5. Isaias IU, Alterman RL, Tagliati M. Deep brain stimulation for primary generalized dystonia: long-term outcomes. Arch Neurol (2009) 66(4):465-70. doi:10.1001/archneurol.2009.20

6. Krauss JK. Surgical treatment of dystonia. Eur J Neurol (2010) 17(s1):97-101. doi:10.1111/j.1468-1331.2010.03059.x

7. Greenberg BD, Gabriels LA, Malone DA, Rezai AR, Friehs GM, Okun MS, et al. Deep brain stimulation of the ventral internal capsule/ventral striatum for obsessive-compulsive disorder: worldwide experience. $\mathrm{Mol}$ Psychiatry (2010) 15(1):64-79. doi:10.1038/mp.2008.55

8. Malone DA, Dougherty DD, Rezai AR, Carpenter LL, Friehs GM, Eskandar EN, et al. Deep brain stimulation of the ventral capsule/ventral striatum for treatment-resistant depression. Biol Psychiatry (2009) 65(4): 267-75. doi:10.1016/j.biopsych.2008.08.029

9. Lozano AM, Giacobbe P, Hamani C, Rizvi SJ, Kennedy SH, Kolivakis TT, et al. A multicenter pilot study of subcallosal cingulate area deep brain stimulation for treatment-resistant depression: clinical article. J Neurosurg (2012) 116(2):315-22. doi:10.3171/2011.10.JNS102122

10. Tomycz ND, Whiting DM, Oh MY. Deep brain stimulation for obesityfrom theoretical foundations to designing the first human pilot study. NeurosurgRev(2012)35(1):37-42; discussion42-3.doi:10.1007/s10143-0110359-9

11. Laxton AW, Tang-Wai DF, McAndrews MP, Zumsteg D, Wennberg R, Keren R, et al. A phase I trial of deep brain stimulation of memory circuits in Alzheimer's disease. Ann Neurol (2010) 68(4):521-34. doi:10.1002/ana. 22089

12. Bittar RG, Kar-Purkayastha I, Owen SL, Bear RE, Green A, Wang S, et al. Deep brain stimulation for pain relief: a meta-analysis. J Clin Neurosci (2005) 12(5):515-9. doi:10.1016/j.jocn.2004.09.001

13. Mori S, van Zijl P. Fiber tracking: principles and strategies - a technical review. NMR Biomed (2002) 15(7-8):468-80. doi:10.1002/nbm.781

14. Calabrese E. Diffusion tractography in deep brain stimulation surgery: a review. Front Neuroanat (2016) 10:45. doi:10.3389/fnana.2016.00045

15. Torres CV, Manzanares R, Sola RG. Integrating diffusion tensor imagingbased tractography into deep brain stimulation surgery: a review of the literature. Stereotact Funct Neurosurg (2014) 92(5):282-90. doi:10.1159/000362937

16. Fenoy AJ, Schiess MC. Deep brain stimulation of the dentato-rubro-thalamic tract: outcomes of direct targeting for tremor. Neuromodulation (2017) 20(5):429-36. doi:10.1111/ner.12585

17. Coenen VA, Varkuti B, Parpaley Y, Skodda S, Prokop T, Urbach H, et al. Postoperative neuroimaging analysis of DRT deep brain stimulation revision surgery for complicated essential tremor. Acta Neurochir (Wien) (2017) 159(5):779-87. doi:10.1007/s00701-017-3134-Z

18. O’Halloran RL, Chartrain AG, Rasouli JJ, Ramdhani RA, Kopell BH. Case study of image-guided deep brain stimulation: magnetic resonance imaging-based white matter tractography shows differences in responders and nonresponders. World Neurosurg (2016) 96:613.e9-613.e16. doi:10.1016/j. wneu.2016.08.103

19. Coenen VA, Rijntjes M, Prokop T, Piroth T, Amtage F, Urbach H, et al. One-pass deep brain stimulation of dentato-rubro-thalamic tract and subthalamic nucleus for tremor-dominant or equivalent type Parkinson's disease. Acta Neurochir (Wien) (2016) 158(4):773-81. doi:10.1007/s00701016-2725-4
20. Coenen VA, Schlaepfer TE, Allert N, Mädler B. Diffusion tensor imaging and neuromodulation: DTI as key technology for deep brain stimulation. Int Rev Neurobiol (2012) 107:207-34. doi:10.1016/B978-0-12-404706-8. 00011-5

21. Coenen VA, Allert N, Mädler B. A role of diffusion tensor imaging fiber tracking in deep brain stimulation surgery: DBS of the dentato-rubrothalamic tract (drt) for the treatment of therapy-refractory tremor. Acta Neurochir(Wien)(2011) 153(8):1579-85; discussion 1585. doi:10.1007/s00701011-1036-Z

22. King NK, Krishna V, Basha D, Elias G, Sammartino F, Hodaie M, et al. Microelectrode recording findings within the tractographydefined ventral intermediate nucleus. JNeurosurg (2017) 126:1669-75 doi:10.3171/2016.3.JNS151992

23. Sammartino F, Krishna V, King NK, Lozano AM, Schwartz ML, Huang Y, et al. Tractography-based ventral intermediate nucleus targeting: novel methodology and intraoperative validation. Mov Disord (2016) 31(8):1217-25. doi:10.1002/mds.26633

24. Coenen VA, Allert N, Paus S, Kronenbürger M, Urbach H, Mädler B. Modulation of the cerebello-thalamo-cortical network in thalamic deep brain stimulation for tremor: a diffusion tensor imaging study. Neurosurgery (2014) 75(6):657-70. doi:10.1227/NEU.0000000000000540

25. Sweet JA, Walter BL, Gunalan K, Chaturvedi A, McIntyre CC, Miller JP. Fiber tractography of the axonal pathways linking the basal ganglia and cerebellum in Parkinson disease: implications for targeting in deep brain stimulation: clinical article. J Neurosurg (2014) 120(4):988-96. doi:10.3171/2013. 12.JNS131537

26. Coenen VA, Mädler B, Schiffbauer H, Urbach H, Allert N. Individual fiber anatomy of the subthalamic region revealed with diffusion tensor imaging: a concept to identify the deep brain stimulation target for tremor suppression. Neurosurgery (2011) 68(4):1069-75. doi:10.1227/NEU. 0b013e31820a1a20

27. Boccard SG, Rebelo P, Cheeran B, Green A, FitzGerald JJ, Aziz TZ. Posttraumatic tremor and thalamic deep brain stimulation: evidence for use of diffusion tensor imaging. World Neurosurg (2016) 96:607.e7-11. doi:10.1016/j. wneu.2016.09.079

28. Klein JC, Barbe MT, Seifried C, Baudrexel S, Runge M, Maarouf M, et al. The tremor network targeted by successful VIM deep brain stimulation in humans. Neurology (2012) 78(11):787-95. doi:10.1212/WNL. 0b013e318249f702

29. Pouratian N, Zheng Z, Bari AA, Behnke E, Elias WJ, DeSalles AA. Multi-institutional evaluation of deep brain stimulation targeting using probabilistic connectivity-based thalamic segmentation: clinical article. J Neurosurg (2011) 115(5):995-1004. doi:10.3171/2011.7.JNS11250

30. Schweder PM, Joint C, Hansen PC, Green AL, Quaghebeur G, Aziz TZ. Chronic pedunculopontine nucleus stimulation restores functional connectivity. Neuroreport (2010) 21(17):1065-8. doi:10.1097/WNR 0b013e32833ce607

31. Rozanski VE, Vollmar C, Cunha JP, Tafula SM, Ahmadi SA, Patzig M, et al. Connectivity patterns of pallidal DBS electrodes in focal dystonia: a diffusion tensor tractography study. Neuroimage (2014) 84:435-42. doi:10.1016/j. neuroimage.2013.09.009

32. Rozanski VE, da Silva NM, Ahmadi SA, Mehrkens J, da Silva Cunha J, Houde JC, et al. The role of the pallidothalamic fibre tracts in deep brain stimulation for dystonia: a diffusion MRI tractography study. Hum Brain Mapp (2017) 38(3):1224-32. doi:10.1002/hbm.23450

33. Coenen VA, Schlaepfer TE, Goll P, Reinacher PC, Voderholzer U, van Elst LT, et al. The medial forebrain bundle as a target for deep brain stimulation for obsessive-compulsive disorder. CNS Spectr (2017) 22:282-9. doi:10.1017/S1092852916000286

34. Makris N, Rathi Y, Mouradian P, Bonmassar G, Papadimitriou G, Ing WI, et al. Variability and anatomical specificity of the orbitofrontothalamic fibers of passage in the ventral capsule/ventral striatum (VC/VS): precision care for patient-specific tractography-guided targeting of deep brain stimulation (DBS) in obsessive compulsive disorder (OCD). Brain Imaging Behav (2016) 10(4):1054-67. doi:10.1007/s11682-015-9462-9

35. Hartmann CJ, Lujan JL, Chaturvedi A, Goodman WK, Okun MS, McIntyre CC, et al. Tractography activation patterns in dorsolateral prefrontal cortex suggest better clinical responses in OCD DBS. Front Neurosci (2016) 9:519. doi:10.3389/fnins.2015.00519 
36. Fenoy AJ, Schulz P, Selvaraj S, Burrows C, Spiker D, Cao B, et al. Deep brain stimulation of the medial forebrain bundle: distinctive responses in resistant depression. J Affect Disord (2016) 203:143-51. doi:10.1016/j.jad. 2016.05.064

37. Schlaepfer TE, Bewernick BH, Kayser S, Mädler B, Coenen VA. Rapid effects of deep brain stimulation for treatment-resistant major depression. Biol Psychiatry (2013) 73(12):1204-12. doi:10.1016/j.biopsych.2013. 01.034

38. Tsolaki E, Espinoza R, Pouratian N. Using probabilistic tractography to target the subcallosal cingulate cortex in patients with treatment resistant depression. Psychiatry Res (2017) 30(261):72-4. doi:10.1016/j.pscychresns. 2017.01.006

39. McNab JA, Voets NL, Jenkinson N, Squier W, Miller KL, Goodwin GM, et al. Reduced limbic connections may contraindicate subgenual cingulate deep brain stimulation for intractable depression: case report. J Neurosurg (2009) 111(4):780-4. doi:10.3171/2009.2.JNS081299

40. Accolla EA, Aust S, Merkl A, Schneider GH, Kühn AA, Bajbouj M, et al. Deep brain stimulation of the posterior gyrus rectus region for treatment resistant depression. J Affect Disord (2016) 194:33-7. doi:10.1016/j.jad.2016. 01.022

41. Riva-Posse P, Choi KS, Holtzheimer PE, McIntyre CC, Gross RE, Chaturvedi A, et al. Defining critical white matter pathways mediating successful subcallosal cingulate deep brain stimulation for treatment-resistant depression. Biol Psychiatry (2014) 76(12):963-9. doi:10.1016/j.biopsych. 2014.03.029

42. Lujan JL, Chaturvedi A, Choi KS, Holtzheimer PE, Gross RE, Mayberg HS, et al. Tractography-activation models applied to subcallosal cingulate deep brain stimulation. Brain Stimul (2013) 6(5):737-9. doi:10.1016/j.brs. 2013.03.008

43. Lujan JL, Chaturvedi A, Malone DA, Rezai AR, Machado AG, McIntyre CC. Axonal pathways linked to therapeutic and nontherapeutic outcomes during psychiatric deep brain stimulation. Hum Brain Mapp (2012) 33(4):958-68. doi:10.1002/hbm.21262

44. Coenen VA, Kieselbach K, Mader I, Reinacher PC. Diffusion tensor magnetic resonance imaging (DTI) tractography-guided deep brain stimulation in neuropathic pain. Acta Neurochir (Wien) (2015) 157(4):739-41. doi:10.1007/ s00701-015-2356-1

45. Hunsche S, Sauner D, Runge MJ, Lenartz D, El Majdoub F, Treuer H, et al. Tractography-guided stimulation of somatosensory fibers for thalamic pain relief. Stereotact Funct Neurosurg (2013) 91(5):328-34. doi:10.1159/ 000350024

46. Boccard SG, Fernandes HM, Jbabdi S, Van Hartevelt TJ, Kringelbach ML, Quaghebeur G, et al. Tractography study of deep brain stimulation of the anterior cingulate cortex in chronic pain: key to improve the targeting. World Neurosurg (2016) 86:361-70. doi:10.1016/j.wneu.2015.08.065

47. Kim W, Chivukula S, Hauptman J, Pouratian N. Diffusion tensor imagingbased thalamic segmentation in deep brain stimulation for chronic pain conditions. Stereotact Funct Neurosurg (2016) 94(4):225-34. doi:10.1159/ 000448079

48. Kovanlikaya I, Heier L, Kaplitt M. Treatment of chronic pain: diffusion tensor imaging identification of the ventroposterolateral nucleus confirmed with successful deep brain stimulation. Stereotact Funct Neurosurg (2014) 92(6):365-71. doi:10.1159/000366002
49. Owen SL, Heath J, Kringelbach ML, Stein JF, Aziz TZ. Preoperative DTI and probabilistic tractography in an amputee with deep brain stimulation for lower limb stump pain. Br JNeurosurg (2007) 21(5):485-90. doi:10.1080/02688690701558358

50. Owen SL, Heath J, Kringelbach M, Green AL, Pereira EA, Jenkinson N, et al. Pre-operative DTI and probabilisitic tractography in four patients with deep brain stimulation for chronic pain. J Clin Neurosci (2008) 15(7): 801-5. doi:10.1016/j.jocn.2007.06.010

51. Elble R, Comella C, Fahn S, Hallett M, Jankovic J, Juncos JL, et al. Reliability of a new scale for essential tremor. Mov Disord (2012) 27:1567-9. doi: $10.1002 / \mathrm{mds} .25162$

52. Goetz CG, Tilley BC, Shaftman SR, Stebbins GT, Fahn S, Martinez-Martin $\mathrm{P}$, et al. Movement Disorder Society-sponsored revision of the Unified Parkinson's Disease Rating Scale (MDS-UPDRS): scale presentation and clinimetric testing results. Mov Disord (2008) 23:2129-70. doi:10.1002/mds.22340

53. Bain PG, Findley LJ, Atchison P, Behari M, Vidailhet M, Gresty M, et al. Assessing tremor severity. JNeurol Neurosurg Psychiatry (1993) 56:868-73. doi:10.1136/jnnp.56.8.868

54. Fahn S, Tolosa E, Marín C. Clinical rating scale for tremor. 2nd ed. In: Jankovic J, Tolosa E, editors. Parkinson's Disease and Movement Disorders. Baltimore: Williams \& Wilkins (1993). p. 225-34.

55. Goodman WK, Price LH, Rasmussen SA, Mazure C, Fleischmann RL, Hill CL, et al. The yale-brown obsessive compulsive scale. I. Development, use, and reliability. Arch Gen Psychiatry (1989) 46(11):1006-11. doi:10.1001/ archpsyc.1989.01810110048007

56. Montgomery SA, Asberg M. A new depression scale designed to be sensitive to change. Br J Psychiatry (1979) 134:382-9. doi:10.1192/bjp.134.4.382

57. Hamilton M. A rating scale for depression. J Neurol Neurosurg Psychiatry (1960) 23:56-62. doi:10.1136/jnnp.23.1.56

58. Hamilton M. Development of a rating scale for primary depressive illness. Br J Soc Clin Psychol (1967) 6(4):278-96. doi:10.1111/j.2044-8260.1967. tb00530.x

59. Beck AT, Steer RA. Beck Depression Inventory manual. San Antonio, TX: The Psychological Corporation (1987).

60. Beck AT, Steer RA, Brown GK. Manual for Beck Depression Inventory II (BDI-II). San Antonio, TX: The Psychological Corporation (1996).

61. Holtzheimer PE, Kelley ME, Gross RE, Filkowski MM, Garlow SJ, Barrocas A, et al. Subcallosal cingulate deep brain stimulation for treatmentresistant unipolar and bipolar depression. Arch Gen Psychiatry (2012) 69(2):150-8. doi:10.1001/archgenpsychiatry.2011.1456

62. Melzack R. The McGill pain questionnaire: major properties and scoring methods. Pain (1975) 1(3):277-99. doi:10.1016/0304-3959(75)90044-5

Conflict of Interest Statement: The authors declare that the research was conducted in the absence of any commercial or financial relationships that could be construed as a potential conflict of interest.

Copyright (c) 2017 See and King. This is an open-access article distributed under the terms of the Creative Commons Attribution License (CC BY). The use, distribution or reproduction in other forums is permitted, provided the original author(s) or licensor are credited and that the original publication in this journal is cited, in accordance with accepted academic practice. No use, distribution or reproduction is permitted which does not comply with these terms. 